


\title{
Health Endowments, Schooling Allocation in the Family, and Longevity: Evidence from US Twins*
}

\author{
Peter A. Savelyev ${ }^{\dagger} \quad$ Benjamin C. Ward ${ }^{\ddagger}$ \\ Robert F. Krueger ${ }^{\S} \quad$ Matt McGue
}

May 24, 2020

\footnotetext{
${ }^{*}$ A version of this paper was presented to the 2019 NBER Health Economics Program Meeting, Boston, USA; The Third Meeting of the Society of Economics of the Household, Lisbon, Portugal; IZA World Labor Conference, Berlin, Germany; Federal Reserve Bank of Richmond Research Seminar; Southern Economic Association 87th Annual Meeting, Tampa, FL; and to the Economics Work-in-Progress Lunch Seminar at the College of William \& Mary. We thank participants of these meetings for helpful suggestions and stimulating discussions. For their comments and suggestions, the authors wish to thank Kathy Anderson, Andrew Goodman-Bacon, Rong Hai, Anna Sanz-de-Galdeano, and four anonymous NSF referees. The authors are especially grateful to Jere Behrman for sharing the data from the Socioeconomic Survey of Twins and commenting on our drafts, and to Federico Gutierrez for his considerable help in conceiving and designing the analysis of schooling allocation in the family. The authors are grateful to Renee Garrow for her research assistance, and to Xiaoyu (Nancy) Chen, Isabel Haber, Eli Rothleder, and Max Sacher for their proofreading of the manuscript. Ward and Savelyev gratefully acknowledge support from the NSF 1460003 grant, Vanderbilt University Department of Economics Faculty-Graduate Student Collaboration Grant, and the Kirk Dornbush Summer Research Grant. Savelyev also benefited from the financial support of the Grey Fund at Vanderbilt and research support from the College of William \& Mary. The views expressed in this paper are those of the authors and do not necessarily reflect the views of the funders.

${ }^{\dagger}$ The corresponding author and an Assistant Professor of Economics at The College of William \& Mary.

$\ddagger$ Lecturer in the Department of Economics at The University of Georgia.

${ }^{\S}$ Hathaway Distinguished Professor of Clinical Psychology in the Department of Psychology at The University of Minnesota, Twin Cities.

IRegents Professor of Psychology in the Department of Psychology at The University of Minnesota, Twin Cities.
} 


\begin{abstract}
We analyze data from the Minnesota Twin Registry (MTR), combined with the Socioeconomic Survey of Twins (SST), and new mortality data, and contribute to two bodies of literature. First, we demonstrate a beneficial casual effect of education on health and longevity in contrast to other twin-based studies of the US population, which show little or no effect of education on health. Second, we present evidence that parents compensate for differences in their children's health endowments through education, but find no evidence that parents reinforce differences in skill endowments. We argue that there is a bias towards detecting reinforcement both in this paper and in the literature. Our compensation result for health endowment holds, as it is obtained despite the bias. We account for observed and unobserved confounding factors, sample selection bias, and measurement error in education.
\end{abstract}

Key words: health endowment, skill endowment, intrafamily resource allocation, education, health, longevity, twin study

JEL codes: I12, I140, I240, J130, J24 


\section{Introduction}

This paper contributes to understanding two controversial questions that are important for both economic theory and policy: (1) whether education causally affects health and longevity and (2) whether parents compensate for or reinforce differences in endowments among their children. As answers to both research questions may differ by country, to inform policy makers in the US it is particularly useful to provide evidence based on quality US data. Our analysis is based on a major dataset of US twins called the Minnesota Twin Registry (MTR), combined with its follow-up survey conducted by economists, called the Socioeconomic Survey of Twins (SST), and our own recent collection of individual mortality data.

The collection of the MTR data began in 1983 in order to identify and study twins born in Minnesota. The SST survey followed up with a subsample of the initial MTR participants. We analyze same-sex twin pairs, in which both twins participated in the SST and both provided information about their education levels. Our estimation sample contains 944 twin pairs born between 1936 and 1955. We match the data from SST to the data from MTR. We then match the resulting MTR-SST data to new data on mortality, which we gathered from the Social Security Death Master File, the National Death Index, and contacts with surviving relatives.

To estimate the effect of education on longevity, we apply a linear probability model to within-pair differences of identical twins in order to estimate the extent to which a twin who has more years of schooling is expected to outlive their twin who has fewer years of schooling. This within-twin-pair approach leverages the common family and genetic background shared by identical twins. We use the same method to study effects of education on health and health behaviors.

To find whether parents compensate for or reinforce differences in health endowments of their children with education, we adopt the method proposed by Behrman et al. (1994) for studying wage earning endowment. For identification, we rely on the presence of identical genes in monozygotic (MZ, or "identical") twins, genetic variation in dizygotic (DZ, or "fraternal") twins, and shared family background for all observed 
twin pairs. In addition, we reanalyze results by Behrman et al. (1994) regarding wage earning endowments using direct measures of wages and earnings from SST (the original paper used earnings imputed from occupations reported in MTR).

We account for a number of econometric issues. By using twin fixed effects we not only control for major confounders, but also control for possible selection biases, including selective attrition (Behrman et al., 1994; Heckman and MaCurdy, 1980; Pitt and Rosenzweig, 1990). To account for measurement error in schooling, we use the well-established Ashenfelter and Krueger (1994) method, which takes advantage of each twins' reports about their own education and the education of their twin. Finally, we control for expected major confounders that could differ across twins: birth weight and disabling injury.

Our first empirical research question regarding the causal effect of education on health and longevity is still debated in the literature. As we discuss in Section 2.1, many authors support the causal effect, while many others argue against it. Because effects of education on health and longevity likely differ from country to country, the most relevant results for our paper to compare to are results based on US datasets. However, the popular compulsory schooling law instrumental variable is weak for the US (Galama et al., 2018), while existing twin data results for the US show either little or no effect of education on health. Our results based on well-established methods and new quality data reverse this conclusion by demonstrating causal effects of education on health and longevity.

Our second research question, whether parents of multiple children tend to reinforce or compensate for differences in their children's endowments, is also empirical, as both results are theoretically possible. The question is controversial, as for every possible result, namely a compensation, a reinforcement, both effects, or neither effect, there is a group of papers that supports it, as summarized in Almond and Mazumder (2013). This great variation in literature results is likely driven by differences in the type of endowment (e.g., skill vs. health endowment), type of investment (e.g., education vs. health investment), type of population (e.g., developed vs. developing country), and type of identification method among other differences. We discuss the literature in Section 2.2 
while taking these differences into account. We contribute to this literature by adding unique data and measures of latent health endowments that are new in this literature.

We argue that there is a bias in the literature towards detecting reinforcement of endowments, which is the most common finding in the literature. Hence, if the true prevailing behavior is compensation, it can be misclassified in a statistical analysis as either reinforcement or "no effect." We are aware of two sources of bias, both going in the same direction. One source of the bias is lack of accounting for children's own decisions on total investments in them. For instance, a sicker child may end up with lower level of education not only because their parents may choose to reallocate educational investments to their healthier child, but also because the sicker child has reduced capabilities and economic incentives to study. Another source of bias comes from not accounting for the effect of endowment on the investment costs (Sanz-de Galdeano and Terskaya, 2019; Terskaya, 2019). We discuss these biases in Section 4.3.

Estimated parameters of our model nominally imply that parents compensate for health endowments with more education but are neutral to skill endowments. When taking the expected bias into account, we can still claim a compensation effect for health endowments, as this result is obtained despite the bias. Our estimates for skills do not support reinforcement even before taking the bias into account. After taking the bias into account, our results do not rule out a possible compensation for skills.

\section{Related Litertaure}

This section complements the introduction by describing results of the literature and our contribution to it in more detail.

\subsection{The Effect of Education on Health and Lonegvity}

Despite a considerable body of literature, the question regarding the causal relationship between education, health, and longevity remains unresolved. This question is often addressed in the literature by using changes in compulsory schooling laws or the birth 
of twins as natural experiments. Other methods include randomized controlled trials, which usually work at low levels of education such as preschool (e.g., Conti et al., 2016), military draft used as instrument for men's education (Buckles et al., 2016), and methods that explicitly model unobserved heterogeneity (e.g., Bijwaard et al., 2015; Conti and Heckman, 2010; Hong et al., 2020; Savelyev, 2020; Savelyev and Tan, 2019). See Grossman (2015) and Galama et al. (2018) for recent surveys.

Compulsory schooling laws identify the effect only for those students who would not gain further education otherwise. The compulsory schooling instrument for the US is weak and therefore it does not lead to a reliable estimation of the effect of interest, while results for other countries are mixed (Galama et al., 2018). For instance, Lleras-Muney (2005) argues that schooling affects mortality in the US, but Mazumder (2008) shows that these results do not survive controlling for state-specific time-trends. Van Kippersluis et al. (2011) find beneficial effects of education on longevity for Dutch men, but Albouy and Lequien (2009) and Meghir et al. (2018) do not find an effect of schooling on longevity for France and Sweden. Similarly, Arendt (2005) and Clark and Royer (2013) find no effect of compulsory schooling on health-related outcomes in Denmark and the UK.

In contrast to compulsory schooling laws, papers using twin fixed effects usually identify the average treatment effect of an additional year of schooling. The use of twin fixed effect identification is limited to available twins registries, among which only a small number are large and old enough to reliably study longevity. Lundborg et al. (2016) use Swedish twins data and find strong effects of education on longevity for both men and women. Madsen et al. (2010) and Behrman et al. (2011) use Danish twins data and find no effects. However, van den Berg et al. (2015) use the same data but a different methodology and find an effect of education on mortality for men but not for women. Behrman et al. (2015) use the Chinese Adult Twins Survey to study effects of education on health and health-related behaviors for a pooled sample of men and women and find a number of effects on important determinants of mortality: improvements in general and mental health, reductions in smoking, and the number of chronic diseases.

There are few findings based on US twins, and they show little or no effect, a result which contrasts with our findings. Kohler et al. (2011) estimate twin fixed effects for 
MZ twins using SST data and conclude that there is no effect of education on health. However, the authors use only one outcome, self-rated health, and perform their estimation only for female twins. We use the same SST data and the same methodology, but instead we investigate both sexes and additional health-related outcomes, including newly collected mortality data, and complement these results with new estimates. ${ }^{1}$ While we confirm the statistically insignificant result reported by Kohler et al. (2011) for self-reported health of women, our estimates for a larger set of health-related outcomes and for both sexes provide evidence in favor of the effect of education on health-related outcomes.

Amin et al. (2015) also use the MTR data and the twin fixed effects estimator, but they combine the MTR data with another dataset called the Mid-Atlantic Twin Registry (MATR) to increase sample size. We compare their results with ours, which are acquired from the MTR data and its follow-ups. The authors report estimates for the pooled sample of men and women only, and concentrate on three health outcomes: self-reported health, BMI, and overweight. Our results for overweight based on the MTR data include a strong and statistically significant sex difference in effects, a strong beneficial effect of education for men, no effect for women, and no statistically significant effect for the pooled sample. Thus, pooling data for overweight-related variables could mask important relationships. Similarly to the authors' estimate, our pooled sample estimate for the effect of education on self-reported health is positive. The authors do not investigate mortality or having specific physical health problems.

\subsection{Family Resource Allocation}

Results in the literature on Family Resource Allocation differ greatly. Some papers show that parents reinforce differences in endowments by investing more in children who have more beneficial endowments (e.g., Adhvaryu and Nyshadham, 2014; Aizer and Cunha, 2012; Almond et al., 2009; Behrman, 1988; Behrman et al., 1982, 1994; Borga and Pidkuyko, 2018; Datar et al., 2010; Frijters et al., 2013; Parman, 2015; Rosenzweig and

\footnotetext{
${ }^{1}$ One difference in methodology is that we control for birth weight and disabling injury, but we find similar effects with and without these controls.
} 
Zhang, 2009; Venkataramani, 2012). Other papers show that parents compensate for differences by investing more in children with less beneficial endowments (e.g., Bharadwaj et al., 2018; Black et al., 2010; Del Bono et al., 2012; Halla and Zweimüller, 2014; Pitt et al., 1990; Sanz-de Galdeano and Terskaya, 2019; Terskaya, 2019). There are also papers that show both compensating and reinforcing effects (e.g., Ayalew, 2005; Hsin, 2012; Restrepo, 2016; Yi, 2019; Yi et al., 2015) and papers that find no or little effect (e.g., Abufhele et al., 2017; Almond and Currie, 2011; Bharadwaj et al., 2013; Kelly, 2011; Nicoletti et al., 2017; Royer, 2009). Almond and Mazumder (2013) survey many of these papers.

However, many papers on family resource allocation are hardly comparable due to different types of child endowments or parental investments they study. Therefore, we split papers into more comparable groups and then discuss them respectively.

We distinguish health endowments from skill endowments and health investments from skill investments, especially given the evidence that the behavior of parents could be either compensating or reinforcing depending on the children's endowment and investment type (e.g., Ayalew, 2005; Nicoletti and Tonei, 2017; Yi et al., 2015).

Since this paper deals with educational investments, we restrict our comparison to a group of papers that study investments in broadly defined skills. We further classify these papers into three groups by their measures of a child's endowment: (1) low birth weight or exposure to adverse environment (a pandemic, nuclear power plant accident, and the like) while in utero or in early childhood (Abufhele et al., 2017; Aizer and Cunha, 2012; Almond and Currie, 2011; Almond et al., 2009; Bharadwaj et al., 2018, 2013; Black et al., 2010; Datar et al., 2010; Halla and Zweimüller, 2014; Hsin, 2012; Kelly, 2011; Nicoletti et al., 2017; Parman, 2015; Restrepo, 2016; Venkataramani, 2012; Yi, 2019); (2) education polygenic score (PGS) (Sanz-de Galdeano and Terskaya, 2019); (3) endowments measured after birth (Ayalew, 2005; Behrman et al., 1982, 1994; Borga and Pidkuyko, 2018; Frijters et al., 2013; Nicoletti and Tonei, 2017; Rosales-Rueda, 2014; Terskaya, 2019; Yi et al., 2015).

These three groups of papers differ in their advantages and disadvantages. The advantage of group (1) is that many of them have a source of arguably exogenous variation, though possible confounders cannot always be ruled out. The advantage of group (2) 
is that genes are determined as early as conception. However, genes may be correlated with family background through the correlation with parental genes. Groups (1) and (2) arguably identify some unknown mixture of skill and health endowments. Health shocks in utero or early childhood may negatively affect not only health but also cognitive skills (e.g., O'Conner et al., 2000). Education PGS predicts not only education, but also health conditional on education (Bolyard and Savelyev, 2019). If health and skill endowments have different effects on investments, then the effect of a mixture depends on mixing weights.

In contrast, measures of health after birth that are used in group (3) are at a bigger risk to be confounded, but they are, usually, more clearly related to either health (e.g., physical disability) or skill (e.g., IQ). This paper is most comparable to the third group of papers and contributes by adding measures of latent health endowments that are new in the literature. Our latent endowments are identified from a structure, the outcomes of which include education, health measures, and longevity. We account for potential confounders by controlling for the twin fixed effects, as well as for potentially confounding observables.

Our paper finds compensation of a health endowment with education. In a robustness check, we show that this result is not driven by wage-earning endowment, which may correlate with our measures of health. In addition, we find that the combined MTRSST data provide no evidence of reinforcement for skills. As we expect our results to be biased towards detecting reinforcement (see Section 4.3 for details), our compensation result for health is still valid, while our statistically insignificant result for skills does not rule out compensation. Since papers from groups (1) and (2) identify effects for some mixture of skill and health endowments, our findings are broadly consistent with those papers that find either evidence of compensation (Bharadwaj et al., 2018; Black et al., 2010; Del Bono et al., 2012; Halla and Zweimüller, 2014; Sanz-de Galdeano and Terskaya, 2019) or a small/negligible effect (Abufhele et al., 2017; Almond and Currie, 2011; Bharadwaj et al., 2013; Kelly, 2011; Nicoletti et al., 2017).

Two papers argue that low-educated mothers reinforce, while high-educated mothers compensate (Hsin, 2012; Restrepo, 2016). We lack statistical power to either confirm or 
reject this result using our data.

Below we compare our paper to the papers from group (3) in more detail, as this group is the most comparable to our paper. We begin with papers that are concerned with health endowment and then proceed with papers about skill endowment.

Health Endowment Measured after Birth and Health Investments Papers in this group show both compensation and reinforcement. However, we see no direct contradiction between our results and papers that find evidence of reinforcement. This is the case because, compared to our paper, each of these papers uses different measures of endowment or a different population, or both.

Rosales-Rueda (2014) uses US data and finds reinforcement for mental health, a separate endowment from the physical health endowment that we study. Ayalew (2005) and Borga and Pidkuyko (2018) study Ethiopia, a country in extreme poverty, where parents face sharp trade-offs. In Ethiopia, giving an extra health investment to a sick child, such as food, can make a difference between life and death, but skipping school has less dramatic consequences. So sick children tend to skip school but get extra food (Ayalew, 2005).

Yi et al. (2015) analyze Chinese twins data and find that when a twin receives a negative health shock between ages 0-3, the other twin receives health investments worth 305 yuan less, but education investments worth 182 yuan more at around age 11. This result implies a compensation of the health shock with health investments, a reinforcement of the health shock with education investments, and a net compensation of the health shock.

There are major differences between developing countries and the US in terms of pension systems, credit constraints, wealth, culture, and financing of medicine and education. Yi et al. (2015) note that parents in developing countries may have an extra motivation to reinforce endowments, because they are more dependent on their children in retirement. Therefore, they may invest more in a child who is more likely to bring back high financial returns. In contrast, US parents are less dependent on their children in retirement and might be more inclined to care about the equality of their children's 
outcomes. This paper is consistent with this intuition, as it finds that US children with lower health endowments are allocated with more schooling.

Two papers from this group show compensation, the same result as in this paper. Terskaya (2019) uses Mexican data for identification of parental preference for equality and argues that even though parents act as if they wish to reinforce disability with less schooling, this result is confounded by different prices of educational investments for healthy and disabled children. Terskaya (2019) argues that parents actually have a preference for equality and compensate for disability conditional on the price effect. $^{2}$ Nicoletti and Tonei (2017) use Australian data and show that parents compensate for health shocks with parental time investments in developmental activities. We complement papers by Terskaya (2019) and Nicoletti and Tonei (2017) by using data from a different country (USA), a different identification method, and different measures of health endowment.

Skill Endowment Measured After Birth and Skill Investments In this group several papers find reinforcement (Ayalew, 2005; Behrman et al., 1994; Frijters et al., 2013; Nicoletti and Tonei, 2017), while results by Behrman et al. (1982) are nuanced. This paper does not confirm reinforcement and, moreover, does not rule out compensation.

Nicoletti and Tonei (2017) use Australian data and argue that parents do not react to changes in cognitive skills but reinforce changes in socio-emotional skills. Ayalew (2005) uses data from Ethiopia, and shows that school attendance is reinforced by skill.

Papers from this group that are, like our paper, based on US data include Behrman et al. (1982, 1994) and Frijters et al. (2013). Frijters et al. (2013) use handedness (right handed vs left handed) as an instrument for cognitive ability differences. They use an index for various parental non-formal education investments. ${ }^{3}$ Behrman et al. (1982) estimate a general preference model based on data on US fraternal white male twins, both of whom served in the U.S. military forces, primarily during the Second World War. The result is nuanced: the authors estimate parameters of the model that are consistent

\footnotetext{
${ }^{2}$ See also Section 4.3 for a discussion of biases that may lead to false detection of reinforcement.

${ }^{3}$ The index for parental investment includes helping their child learn the alphabet, reading stories, having books, etc.
} 
with reinforcement, however, they find that parents do care about equality and their behavior is significantly different from that in a pure investment model. We discuss results of another paper by Behrman et al. (1994) in more detail in Section 5.4, in which we argue that there is no contradiction between our results and results by Behrman et al. (1994) that are based on the MTR data.

Twins vs. Siblings The extent to which our results are applicable for non-twin siblings is an important question. Bharadwaj et al. (2018) conjecture that parents find it easier to compensate when siblings are not exactly the same age. Sanz-de Galdeano and Terskaya (2019) also find evidence consistent with this idea. We do not have data on siblings who are not twins, but find evidence of compensation for twins. Therefore, we can expect compensation for non-twins as well.

\section{Data}

We combine three datasets, which longitudinally describe the lives of twin pairs who were born in Minnesota. Each pair in the sample was raised together.

Minnesota Twin Registry As described in Krueger and Johnson (2002), the MTR was initiated in 1983 and includes data on twins born in Minnesota between 1936 and 1955. The MTR staff identified the twins retrospectively from their birth records and contacted twins to ask for their participation in surveys in person, by mail, and over the telephone. Approximately $80 \%$ of the identified twins were located. Among those located, approximately $80 \%$ agreed to participate. There were 4,307 twin pairs in which both twins participated. MTR participants answered survey questions about an array of topics, including their education and health backgrounds. The MTR gathered participants' birth weight data directly from their birth certificates.

Socioeconomic Survey of Twins In 1994, MTR respondents from same-sex twin pairs were resurveyed by economists in the SST, which gathered further information from each 
twin regarding their labor market participation, wages, health, and education. SST respondents were also asked to provide information about their parents, siblings, spouses, and children. Importantly for our analysis, the SST asked each twin to report education for both themself and the other twin, meaning that we have two separate observations on years of schooling for each twin. 1,325 intact twin pairs returned valid SST questionnaires (Behrman and Rosenzweig, 2002). ${ }^{4}$ The SST has been used in a number of influential publications in economics (e.g., Antonovics and Town, 2004; Behrman and Rosenzweig, 2002, 2004).

Mortality Data To construct mortality data for these twins, we gathered data from both the Social Security Death Master File and the Centers for Disease Control and Prevention's National Death Index. Research found that over $90 \%$ of deaths are correctly identified by each database (Hauser and Ho, 2001; Wentworth and Rasmussen, 1983). We improve the accuracy of the mortality data by comparing data from alternative sources, including data from contacting next-of-kin. The available mortality data up to year 2014 provides us with a 20-year risk period window between the initial date when living twins participated in the SST and the date when the mortality status of respondents was last observed.

Characteristics of the Twin Sample The MTR sample is almost entirely white, which is consistent with the historical demographics of Minnesota. We exclude two twin pairs with at least one non-white parent from the estimation sample, since the data are insufficient for a reliable study of the minority population. ${ }^{5}$ Our twin sample thus consists of twin pairs who are white and of the same sex, who participated in the SST survey, and in which both twins provided education information. This gives us a sample of 674 male and 1214 female twins, whose characteristics are defined and described in Table 1. Although twins are generally similar to one another, on average they differ in education level by over one year. Twins have lower birth weight than singletons. Otherwise, MTR twins are reasonably representative of their Minnesota birth cohort (Krueger and

\footnotetext{
${ }^{4}$ See Behrman and Rosenzweig (1999) for a more thorough description of the SST.

${ }^{5}$ In 1960, non-whites represented 1.2\% of Minnesota's total population (US Census Bureau, 1960).
} 
Table 1: Summary Statistics

\begin{tabular}{|c|c|c|c|c|c|}
\hline \multirow[b]{2}{*}{ Variable } & \multirow[b]{2}{*}{$\begin{array}{c}\text { Year } \\
\text { measured }\end{array}$} & \multicolumn{2}{|c|}{ Males } & \multicolumn{2}{|c|}{ Females } \\
\hline & & Mean & $\begin{array}{l}\text { Std. } \\
\text { dev. }\end{array}$ & Mean & $\begin{array}{l}\text { Std. } \\
\text { dev. }\end{array}$ \\
\hline \multicolumn{6}{|l|}{ (A) Individual Twins } \\
\hline Year of birth & At birth & 1947.7 & 5.4 & 1947.9 & 5.6 \\
\hline Birth weight in pounds & At birth & 5.96 & 1.14 & 5.68 & 1.11 \\
\hline Monozygotic $^{(a)}$ & 1983 & 0.61 & 0.49 & 0.58 & 0.49 \\
\hline Ever had a disabling injury? $?^{(b)}$ & 1983 & 0.32 & 0.47 & 0.33 & 0.47 \\
\hline Years of education ${ }^{(\mathrm{c})}$ & 1994 & 15.1 & 2.3 & 14.1 & 2.2 \\
\hline Physical health problems ${ }^{(\mathrm{d})}$ & 1994 & 0.51 & 0.50 & 0.51 & 0.50 \\
\hline Self-reported health ${ }^{(\mathrm{e})}$ & 1994 & 4.42 & 0.64 & 4.36 & 0.66 \\
\hline $\mathrm{BMI}^{(\mathrm{f})}$ & 1994 & 26.60 & 3.58 & 25.42 & 5.16 \\
\hline Overweight ${ }^{(g)}$ & 1994 & 0.66 & 0.47 & 0.42 & 0.49 \\
\hline Alcohol problems ${ }^{(\mathrm{h})}$ & 1994 & 0.045 & 0.206 & 0.016 & 0.124 \\
\hline Died before 2015 & 1994-2014 & 0.096 & 0.295 & 0.063 & 0.244 \\
\hline Age at death if died & $1994-2014$ & 62.8 & 7.6 & 62.9 & 8.8 \\
\hline \multicolumn{6}{|l|}{ (B) Twin Pairs } \\
\hline Both died before 2015 & 1994-2014 & 0.03 & 0.17 & 0.02 & 0.14 \\
\hline At least one died before 2015 & $1994-2014$ & 0.16 & 0.37 & 0.11 & 0.31 \\
\hline \multicolumn{6}{|l|}{ Absolute difference within pairs } \\
\hline Birth weight, pounds & At Birth & 0.68 & 0.77 & 0.69 & 0.61 \\
\hline Ever had a disabling injury ${ }^{(b)}$ & 1983 & 0.13 & 0.33 & 0.12 & 0.32 \\
\hline Education, years ${ }^{(\mathrm{c})}$ & 1994 & 1.52 & 1.62 & 1.19 & 1.42 \\
\hline Physical health problems ${ }^{(\mathrm{d})}$ & 1994 & 0.42 & 0.49 & 0.38 & 0.49 \\
\hline Self-reported health ${ }^{(\mathrm{e})}$ & 1994 & 0.53 & 0.63 & 0.51 & 0.61 \\
\hline $\mathrm{BMI}^{(\mathrm{f})}$ & 1994 & 2.65 & 2.33 & 3.51 & 3.54 \\
\hline Overweight ${ }^{(g)}$ & 1994 & 0.29 & 0.46 & 0.30 & 0.46 \\
\hline Alcohol problems ${ }^{(\mathrm{h})}$ & 1994 & 0.07 & 0.26 & 0.03 & 0.17 \\
\hline Age at death if both died & 1994-2014 & 4.90 & 5.16 & 8.00 & 6.30 \\
\hline Number of individuals & & \multicolumn{2}{|c|}{674} & \multicolumn{2}{|c|}{1214} \\
\hline
\end{tabular}

Notes: "Std. dev." stands for "standard deviation." (a) Twin respondents are classified in the MTR data as monozygotic or dizygotic based on responses to a questionnaire for parents designed to determine the degree of similarity between twins. (b)Suffered from any disabling injury by 1983 . (c) We use the code by Antonovics and Goldberger (2005) for calculating the effective years of schooling from the raw SST responses. ${ }^{(d)}$ Respondents experienced any of the following: migraine headaches; hay fever; frequently occurring skin rash; hearing impairment; high blood pressure; heart condition; and loss of function in the neck, back, arms, or legs. ${ }^{(\mathrm{e})}$ On a scale from 1 (bad) to 5 (excellent); ${ }^{(\mathrm{f})}$ Weight in kilograms divided by square of height in meters. (g) Overweight is a dummy=1 if BMI $>25$; (h) Any "family, job, or health problems due to alcohol use." 
Johnson, 2002).

For coding the total effective years of schooling, we follow a procedure by Antonovics and Goldberger (2005) designed for the same SST data, in which years of schooling are defined based on the highest degree achieved as well as any additional reported schooling beyond the highest degree. ${ }^{6}$

\section{Methodology}

We apply a linear probability model to within-twin-pair first differences among MZ twins in order to determine the effect of education on health outcomes. We then compare the results for $\mathrm{MZ}$ twins to those for $\mathrm{DZ}$ twins in order to characterize the manner in which families allocate educational resources among siblings with different health endowments.

Linear models have the advantage of well-established use of essential techniques: differencing between twins (to account for sample selection and unobserved heterogeneity) combined with instrumenting noisy differences (to account for measurement error). Not surprisingly, the linear probability model is a common choice in analyses of twin data, including studies of mortality outcomes (e.g., Almond et al., 2005; McGovern, 2019).

\subsection{Model of Schooling Decision and Health}

Behrman et al. (1994) lay out a model for determining schooling and wages for twins. We adapt this model to the case of schooling and health outcomes as follows.

Consider a family $j$ with twin children $i$ and $k$. The family allots $S$ years of schooling to each twin according to the equations

$$
S_{i j}=\alpha_{1} a_{i j}+\alpha_{2} a_{k j}+\delta h_{j}+f_{j}+\boldsymbol{\alpha}_{3} \boldsymbol{x}_{i j}+u_{i j}
$$

\footnotetext{
${ }^{6}$ For example, a high school degree is coded as 12 years of schooling or a college degree as 16 . A twin who reports a high school degree plus one year of college will be coded 13 years of schooling. However, a twin who has not completed a particular degree is only at most coded with the years associated with that degree minus one, regardless of how many years they report. Thus a twin who reports a high school degree plus five years of college but no college degree will be coded with 15 years rather than 17 .
} 
and

$$
S_{k j}=\alpha_{1} a_{k j}+\alpha_{2} a_{i j}+\delta h_{j}+f_{j}+\boldsymbol{\alpha}_{3} \boldsymbol{x}_{k j}+u_{k j}
$$

Here, $a_{i j}$ and $a_{k j}$ represent individual-specific genetic health endowments ${ }^{7} ; h_{j}$ represents common endowments; $f_{j}$ represents family environment; $\boldsymbol{x}_{i j}$ and $\boldsymbol{x}_{k j}$ represent vectors of possible confounders - in our case, birth weight and history of disabling injury; $u_{i j}$ and $u_{k j}$ are random shocks to educational attainment.

Mortality outcomes $M$ for each twin are determined by equations:

$$
M_{i j}=\beta_{1} S_{i j}+a_{i j}+h_{j}+\gamma f_{j}+\boldsymbol{\beta}_{2} \boldsymbol{x}_{i j}+v_{i j}
$$

and

$$
M_{k j}=\beta_{1} S_{k j}+a_{k j}+h_{j}+\gamma f_{j}+\boldsymbol{\beta}_{2} \boldsymbol{x}_{k j}+v_{k j}
$$

where $v_{i j}$ and $v_{k j}$ are random shocks to health.

$\beta_{1}$ is a key parameter of interest. Establishing that $\beta_{1}<0$ would imply that additional years of schooling reduce mortality. Other key parameters are $\alpha_{1}$ and $\alpha_{2}$, which describe the own- and cross-effects of individual health endowments on the family's distribution of educational resources between twins. If $\alpha_{1}<0$ and $\alpha_{2}>0$ (case 1), this implies that families reinforce differences in health endowments by increasing years of schooling for the better-endowed twin (the twin with the lower value of $a$ ) at the expense of the worseendowed twin. ${ }^{8}$ If we have $\alpha_{1}>0$ and $\alpha_{2}<0$ (case 2 ), this would imply that families instead compensate for differences in health endowments. Finally, $\alpha_{1}=\delta$ and $\alpha_{2}=0$ (case 3) would imply that the educational investment for each twin is set individually and is unrelated to the other twin's endowment. Other health-related outcomes are modeled using the same type of equations that we use for mortality.

In this classification of cases 1-3 we follow the standard implicit assumption of the literature that schooling outcomes represent parental resource allocation decisions and

\footnotetext{
${ }^{7}$ In the mortality model and other models with adverse final outcome, variables $a_{i j}$ and $a_{k j}$ are interpreted as "negative health endowments" based on structure of Equations (1-4): they positively affect mortality in equations (3) and (4).

${ }^{8}$ The signs of these relationships are reversed from those described in Behrman et al. (1994), since we normalize the latent health endowment associated with the adverse outcome of mortality, while they normalize the latent wage-earning endowment associated with the beneficial outcome of wage.
} 
that costs of investments are independent of endowments. In Section 4.3 we discuss the bias towards detecting reinforcement that is induced by these assumptions.

\subsection{Within-Twin-Pair First Differences}

MZ twins have identical genetic endowments, so that for MZ twin pairs in our model, $a_{i j}=a_{k j}$. Taking the difference between Equations (1) and (2) yields the following equations for the difference in years of schooling and for the difference in mortality among MZ twin pairs:

$$
\Delta S_{j}^{M}=\boldsymbol{\alpha}_{3} \Delta \boldsymbol{x}_{j}^{M}+\Delta u_{j}^{M}
$$

and

$$
\Delta M_{j}^{M}=\beta_{1} \Delta S_{j}^{M}+\boldsymbol{\beta}_{2} \Delta \boldsymbol{x}_{j}^{M}+\Delta v_{j}^{M},
$$

from which we are able to identify $\beta_{1}$.

$\mathrm{DZ}$ twins have different genetic endowments, so the analogous equations for DZ twin pairs are:

$$
\Delta S_{j}^{D}=\left(\alpha_{1}-\alpha_{2}\right) \Delta a_{j}+\boldsymbol{\alpha}_{3} \Delta \boldsymbol{x}_{j}^{D}+\Delta u_{j}^{D}
$$

and

$$
\Delta M_{j}^{D}=\beta_{1} \Delta S_{j}^{D}+\Delta a_{j}+\boldsymbol{\beta}_{2} \Delta \boldsymbol{x}_{j}^{D}+\Delta v_{j}^{D} .
$$

In the system of equations represented by Equations (5)-(8), $\alpha_{1}$ and $\alpha_{2}$ are not individually identified. However, as shown by Behrman et al. (1994), if we assume that the individual-specific stochastic components $v_{i j}$ and $u_{i j}$ are drawn from the same distribution for both MZ and DZ twins-then the difference $\left(\alpha_{1}-\alpha_{2}\right)$ is identified and can be calculated in the following way:

$$
\alpha_{1}-\alpha_{2}=\frac{1-R}{\beta_{1}^{D}-\beta_{1}^{M}}
$$

where $0<R \equiv \frac{\operatorname{var}\left(\Delta S^{M}\right)}{\operatorname{var}\left(\Delta S^{D}\right)}<1$, and $\beta_{1}^{D}$ and $\beta_{1}^{M}$ represent the estimates from Equation (6) for the DZ and MZ twin subsamples, respectively. (Here we ignore the important issue of measurement error that we address below in Section 4.4.) 
As $R<1$, the sign of $\left(\alpha_{1}-\alpha_{2}\right)$ matches the sign of $\left(\beta_{1}^{D}-\beta_{1}^{M}\right)$. Identification of this difference is sufficient to determine the type of allocation behavior of families, as discussed in the end of Section 4.1. However, we recommend taking into account not only the estimated sign of $\left(\alpha_{1}-\alpha_{2}\right)$, but also the bias towards detecting reinforcement, as we discuss in Section 4.3.

Another benefit of using twin fixed effects is controlling for selection biases (Behrman et al., 1994; Heckman and MaCurdy, 1980; Pitt and Rosenzweig, 1990). A selection bias can be viewed as an omitted variable bias (Heckman, 1979). As long as the omitted variable that controls for selection is family-specific, the twin fixed effects model controls for it. For instance, twin pairs might be selectively attritted due to low common health or skill endowments. Selection into birth in Minnesota may depend on parental background, such as Scandinavian origin. Selection into being a twin could be affected by maternal genes, health, or prenatal environment. ${ }^{9}$

\subsection{Biases towards Detecting Reinforcement that are Inherent in the Literature}

We argue that there are two biases towards detecting reinforcement, the outcome that is the most common finding in the literature. ${ }^{10}$ Our study is subject to both biases described below. However, our detection of compensation despite the expected bias against detecting it only strengthens the conclusions of this paper.

The first type of bias is due to a child's own influence on decisions about investment in their education. It is implicit in the methodology of many papers in the literature that investments are purely determined by parental choice. While this assumption might be true for certain specific parental investments, such as taking a baby to the doctor's office, we argue that for many investments, the child's own actions affect the total investment.

For instance, the total number of effective years of education, which is used in this paper as a measure of parental investment, is arguably affected by both parental and

\footnotetext{
${ }^{9}$ E.g., through genetic predisposition for multiple ovulation or through selective miscarriage (Bhalotra and Clarke, 2019).

${ }^{10}$ The literature on intrafamily resource allocation is surveyed in Section 5.3. The two biases are not necessarily present in every single study, but are typical for existing studies.
} 
children's decisions. On their part, parents can encourage children to study, help them with schoolwork, hire a tutor, and support their college education. However, because of their poor endowment, children may be either unable or unwilling to study hard enough to achieve a certain education threshold. Being unable to study hard is a direct effect of poor endowment on educational investment. For instance, a sick child may be willing but physically unable to concentrate on learning for a sufficient amount of time. Being unwilling to study hard may come from higher psychological costs of studying and from economic incentives. In particular, it takes more effort to study when one's endowment is poor. In addition, the student may expect that additional education may not be productive enough for the desired career in cases when endowments and education are complementary for performance. Finally, poor endowment may imply shorter life expectancy, leading to smaller expected lifetime return from education and therefore reduced economic incentives to study (Becker, 2007).

Therefore, while parental propensity to allocate resources could be either compensating, reinforcing, or neutral, a child's own contributions to the final allocation of resources can be expected to be complementary with the child's own endowment, and so it should lead to a bias towards detecting parental reinforcement. The complementarity between a person's own endowment and investment in human capital is consistent with Becker (2007).

The second type of bias is due to the unaccounted-for price effect. As Terskaya (2019) argues, inequality-averse parents may still reinforce the differences in children's endowments due to the higher relative price of investing in children with lower endowments. The dependence of parental investment costs on the child's endowment was first modeled by Becker and Tomes (1976). Terskaya (2019) and Sanz-de Galdeano and Terskaya (2019) offer empirical approaches that control for the price effect and thus disentangle parental inequality aversion from the price effect. In contrast, traditional methods based on family fixed effect, identify a mixture of inequality aversion and the price effect. However, controlling for the price effect comes at a cost of making additional assumptions and not being able to use family fixed effects or twin fixed effects to account for 
endogeneity problem. ${ }^{11}$

\subsection{Addressing Measurement Error through Instrumental Variables}

As Griliches (1979) points out, the attenuation bias due to measurement error is particularly troublesome in estimates derived from twin data. For instance, when we take the difference of education levels of twins, we can expect a small level of the difference (as twins tend to have similar education levels) combined with an amplified measurement error. Ashenfelter and Krueger's (1994) elegant instrumental variables approach is designed to correct the large attenuation bias that we can expect in this situation. This approach uses one twin's report of the intra-twin-pair difference in education as an instrument for the other twin's report of the same difference. We apply this IV approach in our analysis, using the 1994 SST survey data in which each twin reported both their own and their twin's education backgrounds.

Consider twins 1 and 2 from a same-sex pair $j$. Let $S_{k}^{i}$ represent twin $i$ 's report of twin $k^{\prime}$ s years of schooling, and let $\Delta_{S i}=\left(S_{1}^{i}-S_{2}^{i}\right), i=1,2$, which is how many more years of schooling twin 1 had than twin 2 based on twin $i$ 's reports. Then the first stage of the two-stage least squares (2SLS) method for each sex in this two-stage least squares framework can be written as

$$
\Delta_{S 1}=a_{0}+b \Delta_{S 2}+c \Delta x_{j}+\epsilon_{j}
$$

In the second stage of this approach, the observed difference in mortality outcomes is regressed on the predicted value of the difference in education $\widehat{\Delta_{S 1}}$, as calculated in the first stage regression:

$$
\Delta M_{j}=\beta_{1} \widehat{\Delta_{S 1}}+\boldsymbol{\beta}_{2} \Delta \boldsymbol{x}_{j}+\Delta v_{j}
$$

Ashenfelter and Krueger demonstrate that this approach generates unbiased estimates of $\beta_{1}$, the coefficient of interest, even when a twin's reports of her own education and of

\footnotetext{
${ }^{11}$ Terskaya (2019) makes a parallel paths assumption, which is similar to the one used in the differencein-difference model, by assuming that schooling level of disabled individuals changes with family size by the same amount as the schooling level of non-disabled individuals. Sanz-de Galdeano and Terskaya (2019) rely on the OLS model combined with estimates of the omitted variable bias due to likely confounders.
} 
her twin's education have measurement errors that are correlated with one another. We estimate bootstrapped standard errors for the estimate of $\beta_{1}$ to account for a two-step procedure.

We estimate versions of (10) and (11) under each of two alternative specifications: (A) no controlling for $\Delta \boldsymbol{x}_{j}$; and (B) controlling for $\Delta \boldsymbol{x}_{j}$, with the missing values for $\Delta \boldsymbol{x}_{j}$ imputed using Markov Chain Monte Carlo (MCMC) multiple imputation as described in Rubin (1987) and Schafer (1997), a method that preserves the variance-covariance matrix of variables in the data. The results from estimating approaches (A) and (B) are very close to one another and both support the conclusions of this paper. We report results for specification (B) in the main text and show a comparison with specification (A) in Table A-1 in the Appendix. The nonessential role of confounding factors that include birth weight in twin fixed effects estimates of the effect of education on mortality is consistent with results by Lundborg et al. (2016).

\section{Empirical Results}

\subsection{Health Outcomes}

The results from our estimation of the first stage regression (10), run separately for MZ and DZ sub-samples, are shown in Table 2. Unsurprisingly, one twin's report of the intra-pair difference in years of schooling is a strong predictor for the other twin's report of the same difference: $F$-statistics range from 160 to 867 , which is evidence of an exceptionally strong instrument given the standard threshold for a strong instrument of approximately nine. ${ }^{12}$

The second-stage Regression (11) estimated based on the samples of MZ twins of each sex allows us to identify the effect of education on health-related outcomes. Specifically, we consider the outcomes of mortality (death within 20 years after the SST survey in 1994), any report of physical health problems, and overall self-reported health.

In light abundant of evidence in the literature that the effects of education on health,

\footnotetext{
${ }^{12}$ For instance, Stock et al. (2002) suggest a threshold of 8.96 for the case of one instrumental variable.
} 
Table 2: First Stage of the 2SLS Approach: Intra-Pair Difference in Years of Schooling as Reported by Twin One Regressed on Intra-Pair Difference as Reported by Twin Two

\begin{tabular}{lrccc}
\hline & & $\begin{array}{c}\text { Pooled } \\
\text { sexes }\end{array}$ & Males & Females \\
\hline Monozygotic & coefficient & $0.780^{* * *}$ & $0.860^{* * *}$ & $0.710^{* * *}$ \\
& standard error & $(0.040)$ & $(0.068)$ & $(0.049)$ \\
& F-statistic & 380 & 160 & 210 \\
\#izygotic & of twin pairs & 558 & 204 & 354 \\
& coefficient & $0.854^{* * *}$ & $0.855^{* * *}$ & $0.850^{* * *}$ \\
& standard error & $(0.029)$ & $(0.039)$ & $(0.039)$ \\
& F-statistic & 867 & 481 & 475 \\
& \# of twin pairs & 386 & 133 & 253 \\
\hline
\end{tabular}

Notes: We use specification (10) for each sex. For the pooled sample we additionally control for a sex dummy. Asterisks represent statistical significance levels: ${ }^{* * *} 1 \%, * * 5 \%, * 10 \%$.

longevity, and a number of health behaviors are non-harmful, we use one-tailed tests for the estimated coefficients on years of schooling in our regressions. ${ }^{13}$

The second stage results are shown in Table 3. For males, each additional year of schooling yields a 3.1 percentage point (PP) drop in the probability of death during the 20 years following the 1994 SST survey. For women, each additional year of schooling is associated with a 3.4 PP decline in the probability of reported physical health problems. Other estimates by sex are not precisely determined, but the signs of these estimated coefficients are all in the direction of health improvement.

However, when we increase statistical power by pooling sexes, the effects on all three health outcomes become statistically significant. On average, one year of schooling decreases mortality by $2.3 \mathrm{PP}$, decreases reporting physical health problems by $2.9 \mathrm{PP}$, and improves self-reported health by 0.045 standard deviations.

Given the lack of a statistically significant relationship between education and mortality among women, the presence of a statistically significant relationship between education and physical health problems may seem puzzling. Symmetrically, results for men seem similarly puzzling, with statistically significant effect on mortality but no such

\footnotetext{
${ }^{13}$ See, for example, Grossman (2015) and Galama et al. (2018), in addition to the discussion of the literature in this paper.
} 
Table 3: Effects of Education on Mortality and Health

\begin{tabular}{|c|c|c|c|c|c|}
\hline & & $\begin{array}{r}\text { Pooled } \\
\text { sexes }\end{array}$ & Males & Females & $\begin{array}{r}\text { Sex } \\
\text { differ- } \\
\text { ence }\end{array}$ \\
\hline Mortality & $\begin{array}{r}\text { coefficient } \\
\text { standard error } \\
\text { \# of twin pairs }\end{array}$ & $\begin{array}{c}-0.023^{* *} \\
(0.012) \\
558\end{array}$ & $\begin{array}{c}-0.031^{* *} \\
(0.018) \\
204\end{array}$ & $\begin{array}{r}-0.015 \\
(0.015) \\
354\end{array}$ & $\begin{array}{c}-0.015 \\
(0.024)\end{array}$ \\
\hline $\begin{array}{l}\text { Physical Health } \\
\text { Problems }\end{array}$ & $\begin{array}{r}\text { coefficient } \\
\text { standard error } \\
\text { \# of twin pairs }\end{array}$ & $\begin{array}{c}-0.029 * * \\
(0.019) \\
694\end{array}$ & $\begin{array}{r}-0.022 \\
(0.028) \\
244\end{array}$ & $\begin{array}{c}-0.034 \text { * } \\
(0.025) \\
450\end{array}$ & $\begin{array}{r}0.012 \\
(0.038)\end{array}$ \\
\hline $\begin{array}{l}\text { Self-reported } \\
\text { Health }\end{array}$ & $\begin{array}{l}\text { coefficient } \\
\text { standard error } \\
\text { \# of twin pairs }\end{array}$ & $\begin{array}{c}0.045^{*} \\
(0.034) \\
680\end{array}$ & $\begin{array}{r}0.061 \\
(0.050) \\
241\end{array}$ & $\begin{array}{r}0.023 \\
(0.048) \\
439\end{array}$ & $\begin{array}{r}0.038 \\
(0.069)\end{array}$ \\
\hline
\end{tabular}

Notes: Results of the second stage of the 2SLS model reported. Bootstrapped standard errors reported from 300 replications. One-tailed $p$-values reported for estimated coefficients on years of education, twotailed for difference in coefficient estimates across sexes. Asterisks represent statistical significance levels: $* * * 1 \%, * * 5 \%, * 10 \%$.

result for physical health problems. However, these results are consistent with the wellestablished fact that women at any given age tend to report worse health than men but are less likely to die than men (Case and Paxson, 2005).

Prior research established that individuals with higher income and education levels consume more healthcare, all else equal (Strauss and Thomas, 1998), which creates a concern for the interpretation of our results. Some health conditions, such as high blood pressure or heart conditions, are likely not known to the respondent without a diagnosis from a medical professional. Accordingly, our coefficient estimates for the physical health problem outcome, which describe the protective effect of education on the probability of reporting awareness of having experienced a physical health problem, likely understate education's effect on the probability of truly experiencing a physical health problem. If the more educated had the same amount of health issues as the less educated but were more aware of them, we would then find a positive effect of education on the probability of reporting health problems. Despite this expected bias toward finding a positive effect, we still find a negative effect, suggesting a substantial true beneficial effect of education on the probability of experiencing health problems. In contrast to self-reported health problems, mortality is an objective measure and is not susceptible 
to the same type of bias.

\subsection{Suggestive Mechanisms of the Effect of Education on Health and Longevity}

We have data on body mass index (BMI) and on alcohol problems, which are among possible mechanisms that drive the effects of education on health and longevity. Twins indicated their height and weight at the time of the SST, from which we generate the BMI variable and a dummy variable for being overweight that is defined as BMI $>25$. The twins also indicated whether they had ever experienced "family, job, or health problems due to alcohol use," which can be viewed as a proxy for alcohol addiction or abuse.

2SLS estimates for the effects of education on BMI, being overweight, and alcohol problems are presented in Table 4. Among men, each additional year of education decreases the BMI index by 0.2 and decreases the likelihood of being overweight by $4.5 \mathrm{PP} .{ }^{14}$ We find no statistically significant relationship between education and BMI or being overweight for women. We also find a $1 \%$ reduction in alcohol-related problems for the pooled sample of men and women, a result which is statistically significant at the $10 \%$ level.

Overall, based on our very limited data on the potential mechanisms, we find solid evidence of the excessive body weight channel for men and weak evidence of alcohol abuse channel for the pooled sample.

\subsection{Intra-Household Allocation of Resources}

As explained in Section 4.2, we can determine whether parents compensate for or reinforce endowment differences in siblings by establishing the sign of $\left(\beta_{1}^{D}-\beta_{1}^{M}\right)$. Our estimates for this difference are shown in Table 5. The statistically significant positive numbers that we find are indicative of compensating behavior, in which the unhealthier twin receives more education. Our estimation results provide some evidence of compen-

\footnotetext{
${ }^{14}$ The effect of years of education on BMI for men was estimated by Behrman et al. (1994) using the same data but the authors found no statistically significant results.
} 
Table 4: Suggestive Mechanisms of the Effect of Education on Health and Longevity

\begin{tabular}{lrrrrr}
\hline & & $\begin{array}{c}\text { Pooled } \\
\text { sexes }\end{array}$ & Males & Females & $\begin{array}{c}\text { Sex } \\
\text { Differ- } \\
\text { ence }\end{array}$ \\
\hline Overweight $^{(a)}$ & $\begin{array}{r}\text { coefficient } \\
\text { standard error }\end{array}$ & -0.010 & $-0.045^{* *}$ & 0.025 & $-0.070^{* *}$ \\
& \# of twin pairs & 670 & 240 & 430 & \\
BMI & coefficient & -0.026 & $-0.202^{*}$ & 0.130 & -0.332 \\
& standard error & $(0.109)$ & $(0.154)$ & $(0.170)$ & $(0.229)$ \\
& \# of twin pairs & 670 & 240 & 430 & \\
Alcohol ${ }^{(b)}$ & coefficient & $-0.012 *$ & -0.016 & -0.009 & -0.007 \\
& standard error & $(0.007)$ & $(0.013)$ & $(0.008)$ & $(0.015)$ \\
& \# of twin pairs & 694 & 244 & 450 & \\
\hline
\end{tabular}

Notes: Effects of education on suggestive mechanisms reported based on the second stage of the 2SLS model. Bootstrapped standard errors reported from 300 replications. One-tailed tests used for overweight, and BMI, and two-tailed for sex differences and for alcohol (there is no consensus in the health economics literature regarding the sign of the relationship between educational attainment and alcohol use). Asterisks represent statistical significance levels: ${ }^{* *} 1 \%, * * 5 \%, * 10 \%$. ${ }^{(a)}$ Refers to $B M I>25$. (b) Refers to "family, job, or health problems due to alcohol use."

sating behavior when health is measured in terms of mortality, and strong evidence of compensating behavior when health is measured in terms of physical health problems. The outcome of self-reported health provides no precisely determined estimate of the difference, however, this outcome is arguably the noisiest.

Since earning may affect health and longevity, our estimates of $\left(\alpha_{1}-\alpha_{2}\right)$ could be biased due to the omission of an unobserved earning ability endowment. The data available for our sample does not include early-life measures of ability, which would allow us to model multi-dimensional endowment. We do, however, have quality data from the SST on the wages and the earnings of male respondents. We leverage these data by re-estimating the DZ-MZ differences in estimates of $\beta_{1}$ as shown in Table 5 with wage as an added regressor. Though wage itself is an endogenous outcome, we argue that this approach provides a useful robustness check. If the DZ-MZ differences are robust to the inclusion of the wage control, this is consistent with our results not being driven by the unobserved wage-earning endowments.

Results from estimating models that include wage as a background control are shown 
Table 5: Difference in Education Coefficients between DZ and MZ Twins, $\left(\beta_{1}^{D}-\beta_{1}^{M}\right)$

\begin{tabular}{lrccc}
\hline & & $\begin{array}{c}\text { Pooled } \\
\text { sexes }\end{array}$ & Males & Females \\
\hline Mortality & $\begin{array}{r}\text { coefficient } \\
\text { standard error }\end{array}$ & $\begin{array}{c}0.026^{*} \\
(0.015)\end{array}$ & $\begin{array}{l}0.036 \\
(0.022)\end{array}$ & 0.019 \\
Physical Health & coefficient & $0.066^{* * *}$ & $0.060^{*}$ & $0.073^{* *}$ \\
Problems & standard error & $(0.024)$ & $(0.036)$ & $(0.032)$ \\
Self-reported & coefficient & 0.026 & 0.027 & 0.040 \\
Health & standard error & $(0.045)$ & $(0.067)$ & $(0.064)$ \\
\hline
\end{tabular}

Notes: Difference in second-stage results of the 2SLS model reported. Bootstrapped standard errors calculated from 300 replications. Asterisks represent statistical significance levels: ${ }^{* * *} 1 \%,{ }^{* *} 5 \%, * 10 \%$.

in Table 6. The estimates of $\left(\beta_{1}^{D}-\beta_{1}^{M}\right)$ show robustness to the change. The mortality results become slightly more precise, the physical health results slightly less so, and the result for self-reported health remains imprecise.

It is possible that parents respond to differences in children's health endowments by reinforcing differences on one margin, while simultaneously compensating on another. This is the finding of Yi et al. (2015), who use Chinese twins data to show that when one twin experiences a negative health shock in childhood, the parents divert educational investments toward the healthier twin (reinforcement) but divert health investments toward the less healthy twin (compensation). Parents compensate more than they reinforce, so the authors find that families' overall behavior is compensatory. In our sample we do not observe information about childhood health investments, e.g. physician visits, so we are unable to identify this kind of multidimensional response to differences in health endowments. However, our findings for US twins indicate that parents divert educational resources toward the less healthy twin, which is the opposite of the finding by Yi et al. (2015) for Chinese twins. Taken together, these results suggest differences in the representative household objective function for Chinese and American families, as we discuss in Section .

Apart from the differences in countries studied in these papers, there are also differences in measures of educational investments and health differences. Yi et al. (2015) 
Table 6: Robustness Check: Difference in Education Coefficients between DZ and MZ Twins, $\left(\beta_{1}^{D}-\beta_{1}^{M}\right)$, with and without Wage Control, Males

\begin{tabular}{lrrr}
\hline & & $\begin{array}{r}\text { No wage } \\
\text { control }\end{array}$ & $\begin{array}{r}\text { Wage } \\
\text { control }\end{array}$ \\
\hline Mortality & $\begin{array}{r}\text { coefficient } \\
\text { standard error }\end{array}$ & $\begin{array}{c}0.036 \\
(0.022)\end{array}$ & $\begin{array}{c}0.039 * \\
(0.023)\end{array}$ \\
Physical Health & coefficient & $0.060^{*}$ & 0.051 \\
Problems & standard error & $(0.036)$ & $(0.036)$ \\
Self-reported & coefficient & 0.027 & 0.073 \\
Health & standard error & $(0.067)$ & $(0.067)$ \\
\hline
\end{tabular}

Notes: Difference in second-stage results of the 2SLS model reported. Bootstrapped standard errors calculated from 300 replications. Two-tailed tests used for the difference in coefficient estimates between DZ and MZ twins. Asterisks represent statistical significance levels: $* * * 1 \%, * * 5 \%, * 10 \%$. We control for the hourly wage for the last year in which the respondent worked when completing the SST survey in 1994.

analyze payments for schooling at age 11, while we analyze the total effective years of schooling. They consider responses to early life health shocks, while we consider latent health endowments, which effects are identified from the structure using education, mid-life health, and longevity as outcomes.

\subsection{Reanalysis of Intrafamily Resource Allocation Induced by Skills}

In this section we apply the same model as above but use earnings and wages as outcomes instead of health and longevity. By doing so we reanalyze a portion of results by Behrman et al. (1994) based on the same method and the same data as in the original paper, but using superior data on the earnings of men. Behrman et al. (1994) did not have access to earnings data and had to impute earnings from occupational data. Since using earnings imputed from occupations as regression outcomes may lead to biased estimates (Saavedra and Twinam, 2020) in addition to reduced statistical power, we use directly measured data on both earnings and wages from the SST survey.

Table 7 presents estimates of $\left(\beta_{1}^{D}-\beta_{1}^{M}\right)$ for earnings and wage models. The sign of $\left(\beta_{1}^{D}-\beta_{1}^{M}\right)$ is informative of the sign of $\left(\alpha_{1}-\alpha_{2}\right)$, as discussed in Section 4.2 , but a 
positive sign should now be interpreted as reinforcement rather than compensation. ${ }^{15}$ The table reports parameters for two model specifications that differ by outcome: (1) $\log$ (earnings), and (2) $\log ($ wage). Specification (2) allows us to better capture skills than specification (1) by separating productivity per hour from the time spent working. We are unable to reject the null hypothesis for any of these two specifications.

Table 7: Estimates of $\left(\beta_{1}^{D}-\beta_{1}^{M}\right)$ for Models using Earnings and Wages as Outcomes, Males

\begin{tabular}{rrr}
\hline & $\begin{array}{r}\text { Log of } \\
\text { earnings }\end{array}$ & $\begin{array}{r}\text { Log of } \\
\text { wage } \\
(1)\end{array}$ \\
\hline estimate & 0.033 & $(2)$ \\
standard error & $(0.047)$ & 0.047 \\
\hline
\end{tabular}

Notes: Differences in 2SLS second-stage coefficients reported. Bootstrapped standard errors calculated from 300 replications. Two-tailed tests are used. Lack of asterisks implies that no results are statistically significant even at the $10 \%$ level.

Results of Table 7 confirm the original results by Behrman et al. (1994) that are based on the MTR data, as the estimated parameters $\left(\beta_{1}^{D}-\beta_{1}^{M}\right)$ are statistically insignificant. ${ }^{16}$ However, given the bias towards detecting reinforcement that we discuss in Section 4.3, statistically insignificant results for $\left(\beta_{1}^{D}-\beta_{1}^{M}\right)$ that we obtain do not necessarily imply neutral behavior of parents. In fact, while this result does not show evidence of a reinforcement, it does not rule out a compensation.

\section{Conclusions}

Using newly collected mortality data for the largest survey of US twins, we provide new evidence that education affects health-related outcomes for both men and women.

\footnotetext{
${ }^{15}$ As discussed in Section 4.1, this interpretation depends on whether the outcome is adverse (like mortality) or beneficial (like wage).

${ }^{16}$ Behrman et al. (1994) cannot reject neutral behavior based on the MTR data, but find reinforcement based on the National Academy of Science-National Research Council (NAS-NRC) Twin Data, as well as on NAS-NRC data merged with MTR data. Reanalyzing the full set of results from Behrman et al. (1994) is beyond the scope of this paper, as we focus on complementary results based on newly collected mortality data for the MTR sample and on understanding health endowments.
} 
We also study educational investments as a parental response to their children's endowments of two kinds: health and skills. We find that parents compensate for health endowments. We do not support reinforcement of skill endowments and do not rule out a possible compensation.

Our results are relevant for both theory and economic policy. The existence of a causal effect of education on health makes education a useful health policy variable in the cases of sub-optimal educational investments due to market failure. Parental responses should be taken into account when the government wishes to design programs that either compensate for or reinforce endowments in an optimal way. Our results are consistent with some inequality reduction already naturally happening on the family level.

\section{A Appendix}

Table A-1: Effects of Education on Health Outcomes, Omitting Background Controls

\begin{tabular}{lrcc}
\hline & & $\begin{array}{r}\text { With } \\
\text { controls }\end{array}$ & $\begin{array}{c}\text { With no } \\
\text { controls }\end{array}$ \\
\hline Mortality & coefficient & $-0.023^{* *}$ & $-0.021^{* *}$ \\
& standard error & $(0.012)$ & $(0.010)$ \\
& \# of twin pairs & 558 & 558 \\
Physical Health & coefficient & $-0.029^{* *}$ & $-0.028^{* *}$ \\
Problems & standard error & $(0.019)$ & $(0.017)$ \\
Self-Reported & \# of twin pairs & 694 & 694 \\
Health & coefficient & $0.045^{*}$ & $0.043^{*}$ \\
& standard error & $(0.034)$ & $(0.033)$ \\
& \# of twin pairs & 680 & 680 \\
\hline
\end{tabular}

Notes: Second-stage 2SLS estimates reported. Results are of the second stage of the 2SLS model reported. Results from pooled sample of male and female MZ twins. Bootstrapped standard errors reported from 300 replications. One-tailed tests are used for coefficients on years of education. Asterisks represent statistical significance levels: ${ }^{* * *} 1 \%,{ }^{* *} 5 \%,{ }^{*} 10 \%$. 


\section{References}

Abufhele, A., J. Behrman, and D. Bravo (2017). Parental preferences and allocations of investments in children's learning and health within families. Social Science $\mathcal{E}$ Medicine 194, 76-86.

Adhvaryu, A. and A. Nyshadham (2014). Endowments at birth and parents investments in children. The Economic Journal 126, 781-820.

Aizer, A. and F. Cunha (2012, September). The production of human capital: Endowments, investments and fertility. Working Paper 18429, National Bureau of Economic Research.

Albouy, V. and L. Lequien (2009). Does compulsory education lower mortality? Journal of Health Economics 28, 155-168.

Almond, D., K. Y. Chay, and D. S. Lee (2005, August). The costs of low birth weight. Quarterly Journal of Economics 120(3), 1031-1083.

Almond, D. and J. Currie (2011). Human capital development before age five. In O. Ashenfelter and D. Card (Eds.), Handbook of Labor Economics, Volume 4B, Chapter 15, pp. 1315-1486. North Holland: Elsevier.

Almond, D., L. Edlund, and M. Palme (2009). Chernobyl's Subclinical Legacy: Prenatal Exposure to Radioactive Fallout and School Outcomes in Sweden. The Quarterly Journal of Economics 124(4), 1729-1772.

Almond, D. and B. Mazumder (2013). Fetal origins and parental responses. Annual Review of Economics 5, 37-56.

Amin, V., J. Behrman, and H.-P. Kohler (2015). Schooling has smaller or insignificant effects on adult health in the US than suggested by cross-sectional associations: New estimates using relatively large samples of identical twins. Social Science $\mathcal{E}$ Medicine 127(C), 181-189.

Antonovics, K. L. and A. S. Goldberger (2005). Does increasing women's schooling raise the schooling of the next generation? Comment. The American Economic Review 95, $1738-1744$.

Antonovics, K. and R. Town (2004). Are all the good men married? Uncovering the sources of the marital wage premium. The American Economic Review 94, 317-321.

Arendt, J. N. (2005). Does education cause better health? A panel data analysis using school reforms for identification. Economics of Education Review 24(2), 149-160.

Ashenfelter, O. and A. Krueger (1994). Estimates of the economic return to schooling from a new sample of twins. American Economic Review 84, 1157-1173. 
Ayalew, T. (2005). Parental preference, heterogeneity, and human capital inequality. Economic Development and Cultural Change 53(2), 381-407.

Becker, G. S. (2007). Health as human capital: Synthesis and extensions. Oxford Economic Papers 59(3), 379-410.

Becker, G. S. and N. Tomes (1976). Child endowments and the quantity and quality of children. Journal of Political Economy 84(4), S143-S162.

Behrman, J. R. (1988). Intrahousehold allocation of nutrients in rural India: Are boys favored? Do parents exhibit inequality aversion? Oxford Economic Papers 40(1), 32-54.

Behrman, J. R., H.-P. Kohler, V. M. Jensen, D. Pedersen, I. Petersen, P. Bingley, and K. Christensen (2011). Does more schooling reduce hospitalization and delay mortality? New evidence based on Danish twins. Demography 48(4), 1347-1375.

Behrman, J. R., R. A. Pollak, and P. Taubman (1982). Parental preferences and provision for progeny. Journal of Political Economy 90(1), 52-73.

Behrman, J. R. and M. R. Rosenzweig (1999). "Ability" biases in schooling returns and twins: A test and new estimates. Economics of Education Review 18, 159-167.

Behrman, J. R. and M. R. Rosenzweig (2002). Does increasing women's schooling raise the schooling of the next generation? The American Economic Review 92, 323-334.

Behrman, J. R. and M. R. Rosenzweig (2004). Returns to birthweight. The Review of Economics and Statistics 86, 586-601.

Behrman, J. R., M. R. Rosenzweig, and P. Taubman (1994). Endowments and the allocation of schooling in the family and in the marriage market: The twins experiment. Journal of Political Economy 102(6), 1131-1174.

Behrman, J. R., Y. Xiong, and J. Zhang (2015). Cross-sectional schooling-health associations misrepresented causal schooling effects on adult health and health-related behaviors: Evidence from the Chinese Adults Twins Survey. Social Science \& Medicine 127, 190-197.

Bhalotra, S. and D. Clarke (2019). Twin birth and maternal condition. The Review of Economics and Statistics. Accepted for publication.

Bharadwaj, P., J. P. Eberhard, and C. A. Neilson (2018). Health at birth, parental investments, and academic outcomes. Journal of Labor Economics 36(2), 349-394.

Bharadwaj, P., K. V. Loken, and C. Neilson (2013). Early life health interventions and academic achievement. The American Economic Review 103(5), 1862-1891.

Bijwaard, G., H. van Kippersluis, and J. Veenman (2015). Education and health: The role of cognitive ability. Journal of Health Economics 42 (2015) 42, $29-43$. 
Black, S. E., P. J. Devereux, and K. G. Salvanes (2010). Small family, smart family? Family size and the IQ scores of young men. Journal of Human Resources 45(1), 33-58.

Bolyard, A. and P. A. Savelyev (2019). Understanding the education polygenic score and its interactions with ses in determining health in young adulthood. SSRN Working Paper http://dx.doi.org/10.2139/ssrn.3397735.

Borga, L. G. and M. Pidkuyko (2018). Whoever has will be given more: Child endowment and human capital investment. CERGE-EI Working Paper Series No. 616.

Buckles, K., A. Hagemann, O. Malamud, M. Morrill, and A. Wozniak (2016). The Effect of College Education on Mortality. Journal of Health Economics, 99-114.

Case, A. and C. H. Paxson (2005, May). Sex differences in morbidity and mortality. Demography 42(2), 189-214.

Clark, D. and H. Royer (2013). The effect of education on adult mortality and health: Evidence from Britain. American Economic Review 103(6), 2087-2120.

Conti, G. and J. J. Heckman (2010). Understanding the early origins of the educationhealth gradient: A framework that can also be applied to analyze gene-environment interactions. Perspectives on Psychological Science 5(5), 585-605.

Conti, G., J. J. Heckman, and R. Pinto (2016). The effects of two influential early childhood interventions on health and healthy behaviour. The Economic Journal 126(596), F28-F65.

Datar, A., M. R. Kilburn, and D. S. Loughran (2010). Endowments and parental investments in infancy and early childhood. Demography 47(1), 145-162.

Del Bono, E., J. Ermisch, and M. Francesconi (2012). Intrafamily resource allocations: a dynamic structural model of birth weight. Journal of Labor Economics 30(3), 657-706.

Frijters, P., D. W. Johnston, M. Shah, and M. A. Shields (2013). Intrahousehold resource allocation: do parents reduce or reinforce child ability gaps? Demography 50(6), 21872208.

Galama, T. J., A. Lleras-Muney, and H. van Kippersluis (2018, September). The effect of education on health and mortality: A review of experimental and quasiexperimental evidence. The Oxford Research Encyclopedia, Economics and Finance (oxfordre.com/economics), 1-96.

Griliches, Z. (1979). Sibling models and data in economics: Beginnings of a survey. The Journal of Political Economy 87, S37-S64.

Grossman, M. (2015). The relationship between health and schooling: What's new? Nordic Journal of Health Economics 3(1), 7-17.

Halla, M. and M. Zweimüller (2014). Parental response to early human capital shocks: evidence from the Chernobyl accident. IZA Discussion Paper No. 7968. 
Hauser, T. H. and K. K. L. Ho (2001). Accuracy of on-line databases in determining vital status. Journal of Clinical Epidemiology 54, 1267-1270.

Heckman, J. J. (1979, January). Sample selection bias as a specification error. Econometrica $47(1), 153-162$.

Heckman, J. J. and T. E. MaCurdy (1980, January). A life cycle model of female labour supply. Review of Economic Studies 47(1), 47-74.

Hong, K., P. Savelyev, and K. Tan (2020). Understanding the mechanisms linking education with longevity. Journal of Human Capital. (Forthcoming).

Hsin, A. (2012). Is biology destiny? Birth weight and differential parental treatment. Demography 49(4), 1385-1405.

Kelly, E. (2011). The scourge of asian flu: In utero exposure to pandemic influenza and the development of a cohort of British children. The Journal of Human Resources 46(4), 669-694.

Kohler, H.-P., J. R. Behrman, and J. Schnittker (2011). Social science methods for twins data: Intergrating causality, endowments, and heritability. Biodemography and Social Biology (57(1)), 88-141.

Krueger, R. F. and W. Johnson (2002). The Minnesota Twin Registry: Current status and future directions. Twin Research 5, 488-492.

Lleras-Muney, A. (2005). The relationship between education and adult mortality in the United States. Review of Economic Studies 72(1), 189-221.

Lundborg, P., C. H. Lyttkens, and P. Nystedt (2016). The effect of schooling on mortality: New evidence from 50,000 swedish twins. Demography (53), 1135?1168.

Madsen, M., A.-M. N. Andersen, K. Christensen, P. K. Andersen, and M. Osler (2010). Does educational status impact adult mortality in Denmark? A twin approach. American Journal of Epidemiology 172.

Mazumder, B. (2008). Does education improve health? A reexamination of the evidence from compulsory schooling laws. Economic Perspectives 32(2), 2-16.

McGovern, M. E. (2019). How much does birth weight matter for child health in developing countries? Estimates from siblings and twins. Health Economics 28, 3-22.

Meghir, C., M. Palme, and E. Simeonova (2018, April). Education and mortality: Evidence from a social experiment. American Economic Journal: Applied Economics 10(2), $234-56$.

Nicoletti, C., K. G. Salvanes, and E. Tominey (2017). Response of parental investments to child's health endowment at birth. Working Paper. 
Nicoletti, C. and V. Tonei (2017). The response of parental time investments to the child's skills and health. University of York: Discussion Papers in Economics.

O'Conner, T., M. Rutter, C. Beckett, L. Keaveney, and J. Kreppner (2000). The effects of global severe privation on cognitive competence: Extension and longitudinal followup. Child Development 71(2), 376-390.

Parman, J. (2015). Childhood health and sibling outcomes: Nurture reinforcing nature during the 1918 influenza pandemic. Explorations in Economic History 58, 22-43.

Pitt, M. M. and M. R. Rosenzweig (1990). Estimating the intrahousehold incidence of illness: Child health and gender-inequality in the allocation of time. International Economic Review 31(4), 969-989.

Pitt, M. M., M. R. Rosenzweig, and M. N. Hassan (1990). Productivity, health, and inequality in the intrahousehold distribution of food in low-income countries. The American Economic Review, 1139-1156.

Restrepo, B. J. (2016). Parental investment responses to a low birth weight outcome: who compensates and who reinforces? Journal of Population Economics 29, 969-989.

Rosales-Rueda, M. F. (2014). Family investment responses to childhood health conditions: Intrafamily allocation of resources. Journal of Health Economics 37, 41-57.

Rosenzweig, M. R. and J. Zhang (2009). Do population control policies induce more human capital investment? Twins, birth weight and China's "one-child" policy. The Review of Economic Studies 76(3), 1149-1174.

Royer, H. (2009). Separated at birth: US twin estimates of the effects of birth weight. American Economic Journal: Applied Economics 1, 49-85.

Rubin, D. B. (1987). Multiple Imputation for Nonresponse in Surveys. Wiley.

Saavedra, M. and T. Twinam (2020). A machine learning approach to improving occupational income scores. Explorations in Economic History 75. Article 101304.

Sanz-de Galdeano, A. and A. Terskaya (2019). Parental human capital investment responses to childen's disability. Universidad de Alicante Working Paper.

Savelyev, P. A. (2020). Conscientiousness, Extraversion, College Education, and Longevity of High-Ability Individuals. SSRN eLibrary. SSRN Working Paper http: //ssrn.com/paper=1715942.

Savelyev, P. A. and K. Tan (2019). Socioemotional skills, education and health-related outcomes of high-ability individuals. American Journal of Health Economics 5(1), 250280 .

Schafer, J. L. (1997). Analysis of Incomplete Multivariate Data. Chapman \& Hall/CRC. 
Stock, J. H., J. H. Wright, and M. Yogo (2002, October). A survey of weak instruments and weak identification in generalized method of moments. Journal of Business $\mathcal{E}$ Economic Statistics 20(4).

Strauss, J. and D. Thomas (1998, June). Health, nutrition, and economic development. Journal of Economic Literature 36(2), 766-817.

Terskaya, A. (2019). Parental human capital investment responses to childen's disability. Universidad de Alicante Working Paper.

US Census Bureau (1960). Decennial census. https: //www. census .gov/prod/www/ decennial.html.

van den Berg, G., L. Janys, and K. Christensen (2015). The effect of education on mortality. IZA working paper.

van Kippersluis, H., O. O'Donnell, and E. van Doorslaer (2011). Long-run returns to education: Does schooling lead to an extended old age? The Journal of Human Resources 46, 695-721.

Venkataramani, A. (2012). Early life exposure to malaria and cognition in adulthood: Evidence from Mexico. Journal of Health Economics 31, 767-780.

Wentworth, Deborah N., N. J. D. and W. L. Rasmussen (1983). An evaluation of the Social Security Administration Master Beneficiary Record File and the National Death Index in the ascertainment of vital status. American Journal of Public Health 73, 1270-1274.

Yi, J. (2019). Endogenous altruism: Theory and evidence from Chinese twins. Journal of Labor Economics 37(1), 247-295.

Yi, J., J. J. Heckman, J. Zhang, and G. Conti (2015, November). Early health shocks, intra-household resource allocation and child outcomes. The Economic Journal 125, F347-F371. 